\title{
Las normas sobre la práctica de la prueba: Reglas IBA, Reglas de Praga o la autonomía de la voluntad
}

\author{
Blanca Gómez de la Torre Gómez* \\ Camila Andrade Moreno** \\ Recibido/Received: 07/08/2020 \\ Aceptado/Accepted: 30/09/2020
}

Sumario: 1. Introducción. 2. Reglas IBA y Reglas de Praga. 2.1. Reglas IBA, de dónde surgen y en qué consisten. 2.2. Reglas de Praga, de dónde surgen y en qué consisten. 2.3. Aplicación internacional. 3. Normativa sobre la prueba en el derecho ecuatoriano. 3.1. Normativa sobre el procedimiento para la actuación de pruebas en la Ley de Arbitraje y Mediación. 3.2. Normativa sobre procedimiento en centros de arbitraje nacionales. 3.3. El acuerdo de las partes como fuente del procedimiento en actuación de pruebas. 3.4. Normativa sobre el procedimiento de admisibilidad, tipo y valoración de la prueba en el COGEP. 4. Síntesis comparativa de las Reglas IBA, Praga y COGEP. 5. ¿Se requiere una reforma legal para incorporar las Reglas IBA o Praga al procedimiento arbitral nacional? 6. Conclusiones.

Resumen: El uso de las Reglas de la IBA sobre la Práctica de la Prueba en el Arbitraje Internacional (Reglas IBA) o las Reglas

* Socia de la firma ECIJA GPA. Abogada por la Pontificia Universidad Católica del Ecuador. Especialista superior en Derecho Procesal por la Universidad Andina Simón Bolívar. Máster en Derecho Comercial Internacional por la Universidad Internacional de la Rioja. Correo electrónico: bgomezdelatorre@ecija.com

** Asociada de la firma ECIJA GPA. Abogada por la Universidad de los Hemisferios. Máster en Análisis Económico del Derecho por la Universidad Complutense de Madrid. Correo electrónico: candrade@ecija.com

B. Gómez de la Torre \& C. Andrade Moreno, "Las normas sobre la práctica de la prueba: Reglas IBA, Reglas de Praga o la autonomía de la voluntad", Revista Ecuatoriana de Arbitraje, No. 11, 2020, pp. 61-89. 
Praga Sobre la Tramitación Eficiente de los Procedimientos en el Arbitraje Internacional (Reglas de Praga) no es una práctica usual en el arbitraje nacional. Este ensayo se orienta a divulgar su contenido y a explorar la posibilidad de su uso con la Ley de Arbitraje y Mediación (LAM) vigente o de requerirse plantear una reforma a la referida Ley.

Palabras Clave: Reglas IBA, Reglas de Praga, COGEP, prueba, autonomía de la voluntad.

\section{Rules about the practice of evidence: IBA Rules, The Prague Rules, or party autonomy}

Abstract: The use of the IBA Rules on the Taking of Evidence in International Arbitration (IBA Rules) or the Rules on the Efficient Conduct of Proceedings in International Arbitration (Prague Rules) is not a common practice in national arbitration. This essay is aimed to publicize its content and to explore the possibility of its use with the current Arbitration and Mediation Law (LAM) or if it is required to propose an amendment to the Law.

Keywords: IBA Rules, Prague Rules, COGEP, evidence, freedom of choice.

\section{INTRODUCCIÓN}

A nivel mundial, la mayoría de los países ha diseñado leyes de arbitraje que proveen el marco legal aplicable para la práctica de este proceso. No obstante, por principio de la autonomía de la voluntad y en aplicación de una de las características más sobresalientes de la institución arbitral, como lo es la flexibilidad, las partes son libres de convenir o pactar el procedimiento que consideren más beneficioso para ellas.

Esta flexibilidad se ve reflejada aún más en la fase probatoria, en donde tanto las partes como los árbitros disponen de amplia libertad 
para determinar diversas reglas aplicables, cuyo límite se encuentra en el respeto al orden público y el debido proceso. Esto quiere decir que, a pesar de la libertad que tienen las partes para llevar a cabo su procedimiento, sí deben hacerlo con sumisión a aquellos principios fundamentales del proceso, que garanticen, al menos, el derecho de contradicción de las partes y el derecho a la defensa. "Naturalmente, derecho procesal no equivale a rito ni formulismo, como tampoco flexibilidad procesal equivale a anarquía"1

Es así como las partes pueden, precisamente, estructurar su proceso de forma tal, que se adapte a las características propias del conflicto, o, en lugar de redactar un procedimiento específico para cada relación jurídica, pueden escoger o modificar, según convenga, las

[n]ormas de procedimiento sean las de una determinada institución o centro arbitral, como las Cámaras de Comercio $\mathrm{u}$ otras entidades especializadas, las que suelen competir en el mercado arbitral, justamente proponiendo reglas y usos de probada eficacia y flexibilidad, en las que procuran lograr un adecuado balance de certidumbre y seguridad sobre cuestiones esenciales, sin sacrificar la flexibilidad y agilidad proverbialmente enunciadas como ventajas del sistema arbitral ${ }^{2}$.

Más aún, las normas que regulan el procedimiento arbitral a nivel internacional, en consideración de la variada confluencia de partes, abogados y árbitros, y con ello, de distintos modelos y tradiciones jurídicas, pretenden dar respuesta a esta cuestión que podría constituir una problemática para el desarrollo del proceso. En materia procesal, especialmente en cuestiones probatorias, el contraste de los principales sistemas, del common law y derecho civil, resulta ser más intenso, cuyo análisis ha revelado diferencias, principalmente, en cuanto

[a]l grado de intervención pública en la prueba, a la estructura del proceso civil, al alcance, sentido y función de la práctica

1. C. Coronel Jones, Arbitraje y Procedimiento, <https://bit.ly/38cQPHd> (24/04/2020).

2. Ibídem. 
probatoria, al régimen de actos introductorios del proceso y a los criterios de relevancia en la admisión de la prueba, al deber de cooperación de las partes y los terceros, a la protección de la privacidad y la confidencialidad e incluso a la conceptuación de la verdad y del modo en que el sistema procesal contribuye a su búsqueda ${ }^{3}$.

Así, el objetivo de este trabajo se centra en examinar las normas para la práctica de la prueba que han sido diseñadas por las Reglas IBA de 2010, cuya esencia pretende proporcionar un procedimiento eficiente para la práctica de la prueba en el arbitraje internacional, así como las Reglas de Praga, conocidas como el nuevo soft law para regir procedimientos arbitrales. Además, en contexto de posibles reformas a la LAM, se analizará la necesidad o no de generar una reforma legal, o si aquellas pretendidas modificaciones o actualizaciones al sistema arbitral local, pueden fácilmente ser adoptadas por los propios centros arbitrales en sus reglamentos.

\section{Reglas IBA y Reglas de Praga}

\subsection{Reglas IBA, de dónde surgen y en qué consisten}

Las Reglas $\mathrm{IBA}^{4}$, las cuales fueron adoptadas originalmente en 1983 bajo el nombre "Reglas Suplementarias de la IBA que regulan la Presentación

3. C. Herrera Petrus, Reflexiones sobre el discovery y otros aspectos probatorios del common law en el arbitraje internacional desde la perspectiva del jurista continental, $<\mathrm{https} / / \mathrm{bit} .1 \mathrm{l} / 3 \mathrm{mPeSj}>$, (28/05/2020).

4. Con el objeto de detectar problemas relativos a la conducta de los abogados en arbitraje internacional, sujetos a diferentes normas que podrían resultar contradictorias, en el año 2008, el Comité de Arbitraje de la IBA estableció un Grupo de Trabajo sobre la Práctica del Abogado en el Arbitraje Internacional. Es así como en el año 2010, se llevó a cabo una encuesta, producto de la cual, según reza del preámbulo de las Directrices, se reveló un cierto grado de incertidumbre en relación con las normas que rigen a la representación de parte en el arbitraje, tales como conflictos de interés, preparación de testigos, el "third-party funding", entre otros. Como consecuencia de lo anterior, la IBA, en el año 2013, publicó las Directrices sobre la Representación de Parte en el Arbitraje Internacional, que proponen estándares de conducta a los abogados, representantes de las partes en un procedimiento arbitral, que, por tanto, complementan y refuerzan las Reglas de la IBA sobre la práctica de la prueba del año 2010.

F. J. Montero \& M. Romero, La Conducta del Abogado y la Práctica de la Prueba en el Arbitraje Internacional, $<\mathrm{https} / / / \mathrm{bit} . l \mathrm{y} / 32 \mathrm{cK} 2 \mathrm{JX}>(11 / 06 / 2020)$. 
y Recepción de Prueba en el Arbitraje Comercial Internacional", cuya primera versión fue posteriormente revisada en 1999, como las "Reglas de la IBA sobre la Práctica de la Prueba en el Arbitraje Comercial Internacional", y finalmente en 2010, la versión revisada de esta última adoptó el nombre de "Reglas de la IBA sobre la Práctica de la Prueba en el Arbitraje Internacional", tienen como objetivo el proporcionar un "procedimiento eficiente, económico y equitativo para la práctica de la prueba en el arbitraje internacional. Las Reglas IBA proporcionan mecanismos para la presentación de documentos, testigos, peritos e inspecciones, así como para el desarrollo de las audiencias en las que dicha prueba se practica" ${ }^{5}$.

Según indica el Preámbulo de las Reglas IBA, este procedimiento está enfocado, particularmente, para aquellos arbitrajes internacionales que surgen entre partes de distintas tradiciones jurídicas, y que, además, pueden ser usadas junto con reglas institucionales, ad hoc o aquellas diseñadas por las partes, de forma tal que estas últimas, así como los tribunales arbitrales, pueden libremente adaptarlas a situaciones individuales de cada proceso.

En otras palabras, las Reglas IBA reflejan procedimientos empleados en diferentes sistemas legales y por ello, pueden ser de particular utilidad cuando las partes provienen de diferentes tradiciones legales $\mathrm{y}$, asimismo, proporcionan al tribunal arbitral, herramientas para determinar la admisibilidad, relevancia, importancia y valor de las pruebas, conforme se describe a continuación.

En relación con el rol del tribunal arbitral, las Reglas IBA, en su artículo 2, numeral 1, obligan al tribunal a consultar a las partes a fin de normar el procedimiento para la práctica de

5. Reglas de la IBA (International Bar Association) sobre Práctica de Prueba en el Arbitraje Internacional (2010). 
la prueba, el que puede referirse, según su numeral segundo, al ámbito, tiempo y forma de la práctica de la prueba. "El Tribunal Arbitral deberá consultar a las Partes tan pronto como sea procedimentalmente posible e invitarlas a consultarse mutuamente a fin de acordar un procedimiento eficiente, económico y equitativo para la práctica de la prueba"6.

El artículo 3, numeral 10, faculta al Tribunal, en cualquier momento antes de la conclusión del arbitraje, a pedir a cualquiera de las partes que exhiba documentos ${ }^{7}$. De otro lado, en relación con la prueba pericial, el artículo 5, numeral 4, faculta al tribunal arbitral a ordenar a los peritos designados por las partes, que vayan a presentar o que hayan presentado dictámenes periciales sobre el mismo asunto o conexos, a que se reúnan y deliberen acerca de tal asunto.

El Tribunal Arbitral podrá, a su discreción, ordenar que los Peritos Designados por las Partes que vayan a presentar o que hayan presentado Dictámenes Periciales sobre los mismos asuntos o sobre asuntos conexos, se reúnan y deliberen acerca de tales asuntos. En dicha reunión, los Peritos Designados por las Partes deberán tratar de llegar a un acuerdo sobre los asuntos a que se refieren sus Dictámenes Periciales y harán constar por escrito aquellos puntos sobre los que lleguen a un acuerdo, así como aquellos otros sobre los que exista desacuerdo y las razones de ello ${ }^{8}$.

Por su parte, el artículo 6, numeral 1, faculta al tribunal arbitral a designar peritos independientes a fin de que se pronuncien sobre cuestiones específicas que este requiera, pero siempre sujeto al pronunciamiento de las partes.

El Tribunal Arbitral, después de consultar a las Partes, podrá designar uno o más Peritos independientes para que dictaminen sobre cuestiones específicas determinadas por el Tribunal Arbitral. El Tribunal Arbitral, previa consulta a las

6. Ibídem, Artículo 2(1).

7. Ibídem, Artículo 3(10).

8. Ibídem, Artículo 5(4). 
Partes, establecerá los términos de la tarea a desarrollar por el Perito. El Tribunal Arbitral remitirá a las Partes una copia de la versión final de esos términos?

El artículo 7 faculta al tribunal, a petición de parte o por iniciativa propia, a inspeccionar o solicitar la inspección por un perito, de cualquier lugar, propiedad, maquinaria o cualesquiera otros bienes, muestras, sistemas, procesos o documentos que considere apropiados.

Sujeto a las disposiciones del Artículo 9.2, el Tribunal Arbitral podrá, a instancia de una Parte o por iniciativa propia, inspeccionar o solicitar la inspección por un Perito Designado por el Tribunal Arbitral o un Perito Designado por las Partes de cualquier lugar, propiedad, maquinaria o cualesquiera otros bienes, muestras, sistemas, procesos o Documentos que considere apropiados. El Tribunal Arbitral deberá, previa consulta a las Partes, determinar el momento y las circunstancias de la inspección. Las Partes y sus representantes tendrán derecho a estar presentes en cualquiera de estas inspecciones ${ }^{10}$.

El artículo 9, numeral 2, se refiere a la facultad del tribunal arbitral de determinar la admisibilidad, relevancia, importancia y valoración de la prueba, señalando los motivos por los cuales puede excluir, a petición de parte, o de oficio, la exhibición de documentos, declaración, testimonio oral o inspección ${ }^{11}$. Esta disposición es de particular importancia, ya que incluye un sistema de objeciones a la práctica de pruebas indebidas, en virtud de la cual, "la reacción tempestiva y diligente de las partes y el buen tino de los árbitros pueden evitar pruebas superfluas o irrelevantes, excesivamente onerosas, lesivas de derechos fundamentales o espacios legítimos de confidencialidad o, en fin, dirigidas a dilatar indebidamente el proceso arbitral"12.

9. Ibídem, Artículo 6(1).

10. Ibídem, Artículo 7.

11. Ibídem, Artículo 9(2).

12. C. Herrera Petrus, N. 3. 
(a) Falta de relevancia suficiente o utilidad para la resolución del caso; (b) existencia de impedimento legal o privilegio bajo las normas jurídicas o éticas determinadas como aplicables por el Tribunal Arbitral; (c) onerosidad o carga excesiva para la práctica de las pruebas solicitadas; (d) pérdida o destrucción del Documento, siempre que se demuestre una razonable probabilidad de que ello haya ocurrido; (e) confidencialidad por razones comerciales o técnicas que el Tribunal Arbitral estime suficientemente relevantes; (f) razones de especial sensibilidad política o institucional que el Tribunal Arbitral estime suficientemente relevantes (incluyendo pruebas que hayan sido clasificadas como secretas por parte de un gobierno o de una institución pública internacional); o (g) consideraciones de economía procesal, proporcionalidad, justicia o igualdad entre las Partes que el Tribunal Arbitral estime suficientemente relevantes.

Según el artículo 9, numeral $5^{13}$, en caso de falta de suministro injustificada de un documento requerido en una solicitud de exhibición de documento, el tribunal arbitral podrá inferir que tal documento es contrario a los intereses de la parte incumplida.

Si una Parte no suministrare, sin explicación satisfactoria, un Documento requerido en una Solicitud de Exhibición de Documentos que ella no hubiera objetado en debido tiempo o no presentara un Documento que el Tribunal Arbitral hubiera ordenado aportar, el Tribunal Arbitral podrá inferir que ese Documento es contrario a los intereses de esa Parte.

Respecto a la producción de prueba documental, el artículo 3 establece requisitos y diseña un procedimiento para el efecto. Así, en el artículo 3, numeral $3^{14}$ se establecen los requisitos para la solicitud de exhibición de documentos, mientras que el numeral $9^{15}$ indica el proceso que debe seguirse para la exhibición de documentos de una persona u organización que no forma parte del arbitraje:

13. Reglas de la IBA (International Bar Association) sobre Práctica de Prueba en el Arbitraje Internacional, N. 5, Artículo 9(5).

14. Ibídem, Artículo 3(3).

15. Ibídem, Artículo 3(9). 
Artículo 3, numeral 3. Una Solicitud de Exhibición de Documentos deberá contener: (a) (i) una descripción de cada Documento cuya exhibición se solicite que sea suficiente para identificarlo, o (ii) una descripción suficientemente detallada (incluyendo el asunto de que se trate) de la concreta y específica categoría de Documentos requeridos que razonablemente se crea que existen; en el caso de Documentos conservados en formato electrónico, la Parte solicitante puede ó el Tribunal Arbitral puede requerirle que proceda a, identificar archivos específicos, términos de búsqueda, individuos o cualquier otro medio de búsqueda para esos Documentos en una forma eficiente y económica. (b) una declaración de por qué los Documentos requeridos son relevantes para el caso y sustanciales para su resolución; y (c) (i) una declaración de que los Documentos requeridos no se encuentran en poder, custodia o control de la Parte que los solicita o una declaración de las razones por las cuales sería irrazonablemente gravoso para la Parte solicitante exhibir tales Documentos, y (ii) una declaración sobre las razones por las cuales la Parte solicitante supone que los Documentos requeridos están en poder, custodia o control de otra Parte.

Artículo 3, numeral 9. Si una de las Partes desea que se exhiban Documentos de una persona u organización que no sea parte del arbitraje y respecto de la cual la Parte no pueda obtener los Documentos por sí misma, tal Parte podrá solicitar, dentro del plazo fijado por el Tribunal Arbitral, que se tomen cualesquiera medidas legalmente disponibles para obtener los Documentos requeridos, o pedir permiso al Tribunal Arbitral para adoptar tales medidas por sí misma. Dicha solicitud deberá ser presentada al Tribunal Arbitral y a las otras Partes por escrito, y deberá contener las especificaciones del Artículo 3.3., en tanto estas fueran aplicables. El Tribunal Arbitral decidirá sobre esa solicitud y adoptará, autorizará a la Parte requirente a adoptar, $\mathrm{u}$ ordenará a cualquiera de las otras Partes que adopten, las medidas que considere apropiadas si, a su criterio, determina que (i) los Documentos serían relevantes para el caso y sustanciales para su resolución, (ii) se han cumplido los requisitos del Artículo 3.3, en cuanto resulten aplicables y (iii) ninguna de las objeciones contempladas en el Artículo 9.2 es de aplicación.

De los artículos transcritos, se desprende que las Reglas IBA han desarrollado mecanismos a fin de paliar el exceso 
de documentación aportada por las partes. Así, según el artículo 3, numeral 3, las partes pueden solicitar que se exhiba un determinado documento o una "concreta y específica categoría de documentos requeridos". En la práctica, incluso la señalización de una concreta y específica categoría de documento puede implicar la presentación de extensos folios. Para ello, las mismas Reglas IBA prevén la facultad del tribunal de denegar tales solicitudes en caso de que a su criterio, no tuvieren relevancia suficiente o supone una carga excesiva para la práctica de las pruebas solicitadas.

Sobre el examen de testigos, el artículo 8, en sus numerales 2 y $5^{16}$, establece un rol proactivo del tribunal arbitral, permitiéndole limitar el número de preguntas que se pueden formular a los testigos:

2. El Tribunal Arbitral tendrá en todo momento pleno control sobre la Audiencia Probatoria. El Tribunal Arbitral podrá limitar o excluir cualquier pregunta, respuesta o comparecencia de un testigo, si considerase que dicha pregunta, respuesta o comparecencia es irrelevante, insustancial, irrazonablemente gravosa, repetitiva o que de alguna otra manera se da alguno de los supuestos que justifique su objeción contemplados en el Artículo 9.2. Las preguntas y repreguntas efectuadas a un testigo durante su interrogatorio no deberán inducir irrazonablemente sus respuestas.

5. Sujeto a lo dispuesto en el Artículo 9.2, el Tribunal Arbitral podrá solicitar a cualquier persona que presente pruebas orales o escritas sobre cualquier asunto que el Tribunal Arbitral considere relevante para el caso y sustancial para su resolución. Cualquier testigo convocado e interrogado por el Tribunal Arbitral también podrá ser interrogado por las Partes.

Finalmente, en caso de que las partes deseen adoptar las Reglas IBA, estas recomiendan adoptar la siguiente redacción

16. Ibídem, Artículos 8(2) y 8(5). 
en el correspondiente convenio arbitral, seleccionando una de las siguientes alternativas:

Además de las reglas institucionales, ad hoc u otras reglas elegidas por las partes, las partes acuerdan que el arbitraje se desarrollará conforme a las Reglas de la IBA sobre Prueba que se encuentran vigentes a la fecha de [este acuerdo/el inicio del arbitraje]'.

Asimismo, las partes y los Tribunales Arbitrales pueden adoptar las Reglas de la IBA sobre Prueba, en todo o en parte, al inicio del arbitraje o en cualquier momento posterior. Podrán también modificarlas o utilizarlas como guías para el desarrollo de su propio procedimiento ${ }^{17}$.

En síntesis, podemos decir que las Reglas IBA proporcionan normas, que como se ha dicho, las partes pueden incorporarlas a su convenio arbitral, en todo o en parte, o incluso una vez iniciado el procedimiento. Este conjunto de normas se caracteriza por contener un equilibrio entre las distintas corrientes procesales, al haber creado precisamente un puente entre ellos. Sin embargo,

[n]o puede sorprender que estas reglas recojan y trasluzcan, entre otras posibilidades, diversos principios y prácticas habituales en el common law, tales como las testificales escritas, la cross-examination de los testigos y el discovery de documentos, si bien todos ellos matizados y con sujeción a aquellas modulaciones que las partes y los árbitros estimen oportunas en cada caso concreto $^{18}$.

\subsection{Reglas de Praga, de dónde surgen y en qué consisten}

Debido a una generalizada insatisfacción de aquellos usuarios del sistema arbitral, principalmente, sobre el tiempo y costos que este proceso implica, se conformó un Grupo de Trabajo, compuesto por representantes de treinta jurisdicciones, de derecho civil, quienes, con la base de las tradiciones

17. Ibídem, p. 3.

18. C. Herrera Petrus, N. 3. 
procedimentales aplicadas en el arbitraje internacional en cada uno de sus países, prepararon un primer borrador de las hoy denominadas Reglas Praga Sobre la Tramitación Eficiente de los Procedimientos en el Arbitraje Internacional, difundidas en enero de 2018 y finalmente adoptadas el 14 de diciembre de 2018, en Praga, República Checa. En opinión de este Grupo de Trabajo, la ineficiencia del sistema arbitral se debe, en suma, a la cantidad de documentos aportados por las partes, la abundancia de testigos y pericias, así como la extensa duración de las audiencias.

Este documento fue, inicialmente, concebido para aquellos procesos arbitrales, cuyas controversias resulten entre compañías radicadas en jurisdicciones de derecho civil; sin embargo, luego de varios debates, y una mejor redacción de este, se verificó que podría ser aplicado a cualquier procedimiento arbitral cuya naturaleza amerite una gestión más proactiva del tribunal arbitral.

De acuerdo con el Preámbulo de las Reglas de Praga, estas nacen con la finalidad no de reemplazar aquellas reglas que han sido facilitadas por varias instituciones arbitrales, sino más bien para completar, en todo o en parte, aquellas que fueren convenidas por las partes, cuya premisa adopta al sistema procesal del derecho civil que exige una mayor intervención del tribunal arbitral, quien está facultado a conducir ampliamente al proceso arbitral, con el fin de lograr mayor eficiencia y reducción de costos. Así, estas serán aplicables ante el acuerdo de las partes o por iniciativa del propio tribunal arbitral, previa consulta a las partes.

Para muchos, las Reglas de Praga nacen como una alternativa a las Reglas IBA, cuya principal característica es la libertad de las partes para normar su procedimiento. Así, las Reglas de Praga determinan una labor más determinante del tribunal arbitral, lo que se encuentra contemplado en el artículo 
$1(2)^{19}$, que establece que este puede aplicar las Reglas de Praga o cualesquiera de sus disposiciones, aún sin el consentimiento de las partes.

Así también, se establece un rol más activo del tribunal respecto al establecimiento de los hechos, toma de prueba y aplicación de distintas disposiciones legales, en observancia al principio iura novit curia. Así lo disponen los artículos 3(1), 5(6), 7, y $9^{20}$.

3.1. El tribunal arbitral está legitimado -y se le alienta- para adoptar la iniciativa en el establecimiento de aquellos hechos del caso que considere relevantes para la resolución de la controversia. Sin embargo, esta iniciativa no liberará a las partes de su carga de la prueba.

7.1. Cada parte tiene la carga de probar sus pretensiones.

7.2. Sin embargo, el tribunal arbitral podrá aplicar disposiciones legales que no hayan sido invocadas por las partes si así lo estima necesario, incluyendo, entre otras, normas imperativas. En estos supuestos, el tribunal arbitral recabará el parecer de las partes sobre las normas legales que intente aplicar. El tribunal arbitral también podrá apoyarse en antecedentes legales -aunque no hayan sido citados por las partes- si se refieren a disposiciones legales alegadas por las partes y siempre que las partes haya [sic.] tenido oportunidad de expresar su parecer sobre su contenido.

9. Asistencia en un Acuerdo Transaccional.

9.1. El tribunal arbitral podrá ayudar a las partes a alcanzar una solución transaccional de la controversia durante cualquier fase del arbitraje, salvo que concurra la objeción de una de las partes.

En cuanto al aporte de documentación, las partes están limitadas sujeto a lo previsto en el artículo $4^{21}$. En primer lugar, las Reglas de Praga invitan a las partes y al tribunal a

19. Reglas Sobre la Tramitación Eficiente de los Procedimientos en el Arbitraje Internaccional (Reglas de Praga) (2018), Artículo 1(2).

20. Ibídem, Artículos 3(1), 5(6), 7 y 9.

21. Ibídem, Artículo 4. 
evitar cualquier método de exhibición documental, incluido el "discovery" electrónico. Esto es, el tribunal arbitral está facultado, bajo esta normativa, a limitar o impedir el aporte excesivo de documentación, incluida aquella electrónica, sin perjuicio del derecho de una de las partes de solicitar al tribunal arbitral, de así considerarlo conveniente, la aportación de determinados documentos en poder de la otra parte, siempre que resulten relevantes y pertinentes para la resolución del caso.

4.2. Como regla general, se invita al tribunal arbitral y a las partes a evitar cualquier método de exhibición documental, incluido el discovery electrónico.

4.3. No obstante, si una parte considera conveniente requerir a la parte contraria la aportación de determinados documentos, deberá indicárselo así al tribunal arbitral en la reunión preliminar, justificando los motivos por los que, en su opinión y en ese asunto específico, puede proceder la exhibición documental. Si el tribunal arbitral resulta convencido de la necesidad de la exhibición documental, deberá prever un incidente de aportación documental e incluir su tramitación en el calendario de actuaciones.

La limitación de testigos también es un asunto del que se han hecho cargo las Reglas de Praga. Así, sus artículos 5(2) y 5(3) $)^{22}$, facultan al tribunal arbitral a excluir aquellos testigos que a su criterio no resulten útiles para la resolución del caso, así como a denegar la práctica del interrogatorio a determinados testigos, por resultar irrelevantes o innecesarios para la resolución de la controversia.

5.2. Después de haber oído a las partes, el tribunal arbitral decidirá los testigos que serán citados para prestar declaración en las audiencias, según los Artículos 5.3 a 5.9 siguientes.

5.3. El tribunal arbitral podrá denegar la práctica del interrogatorio de determinados testigos durante la audiencia antes o después de la aportación al procedimiento de su declaración testifical escrita; especialmente, si considera que tal declaración es irrelevante, superflua, demasiado gravosa,

22. Ibídem, Artículos 5(2) y 5(3). 
reiterativa o, por cualquier otro motivo, innecesaria para la resolución de la controversia.

En cuanto al examen de testigos, el tribunal arbitral está también facultado para limitar el interrogatorio de estos, incluso cuando existiere una declaración testifical por escrito:

5.5. El tribunal arbitral, si así lo estima pertinente, podrá invitar a una parte a aportar la declaración testifical escrita de un determinado testigo antes de la audiencia.

5.6. Si una parte aporta una declaración testifical escrita sobre la base del Artículo 5.4 o tras la invitación del tribunal arbitral del Artículo 5.5, el tribunal arbitral, una vez oídas las partes, podrá denegar, pese a todo, la práctica de la declaración de ese testigo durante la audiencia ${ }^{23}$.

En definitiva, las Reglas de Praga traen consigo un enfoque del derecho continental, al otorgar facultades al tribunal arbitral que suponen un rol más proactivo de este. Entre estas facultades, podríamos destacar aquella sujeta a la aplicación del principio iura novit curia y la asistencia en la solución amistosa del conflicto. De acuerdo con la primera, las partes estarían liberadas, de alguna manera, de hacer un examen exhaustivo de toda la normativa que fundamente su alegación. De acuerdo con la segunda, las Reglas de Praga dicen que el tribunal arbitral podría asistir a las partes a alcanzar un acuerdo amistoso, siempre y cuando ello esté permitido por la lex arbitri.

\subsection{Aplicación internacional}

El arbitraje internacional es un espacio de encuentro de distintas culturas procesales, especialmente, en materia probatoria. A pesar de que existen varias instituciones arbitrales y legislaciones nacionales en esta materia, estas no

23. Ibídem, Artículos 5(5) y 5(6). 
han desarrollado de forma amplia aquellas normas sobre la práctica de la prueba aplicable al arbitraje.

Lo anterior, en gran medida, se debe justamente al principio de autonomía de la voluntad de las partes, así como el de flexibilidad, que les permite adecuar el proceso de la forma que mejor convenga. Ello, además, constituye uno de los principales motivos por el que el proceso arbitral resulta llamativo; se trata de un foro neutral, en donde las partes pueden hacer uso de diferentes sistemas procesales, incluso adecuándolo a su mejor criterio, lejos de los habituados respectivos tribunales de justicia ordinarios.

Así, el arbitraje internacional resulta en un espacio de encuentro, que permite la confluencia de distintas tradiciones jurídicas, que trata de alguna manera, de abstraer aquellos beneficios de cada uno de ellos, y como consecuencia de lo anterior, obtener un mismo procedimiento que resulte ventajoso para las partes, de acuerdo con las características particulares de su controversia.

Las Reglas IBA y las Reglas de Praga constituyen ejemplos del soft law que resultan aplicables para la práctica arbitral internacional, las cuales, devienen de un propósito de proporcionar guías eficientes para la práctica de la prueba, que concilien los diversos sistemas jurídicos mundiales. Mientras las Reglas IBA lo hacen en un espíritu integrativo de los sistemas del derecho de comunes y el derecho contintental, las Reglas de Praga parten de una concepción eminentemente apegada al derecho continental. Ambas, sin embargo, tienen como fin una mejora del sistema arbitral, que permita llevar a cabo un proceso eficiente a través de la reducción de costos y tiempo. 


\section{NoRMATIVA SOBRE LA PRUEbA EN EL DERECHO ECUATORIANO}

\subsection{Normativa sobre el procedimiento para la actuación de pruebas en la Ley de Arbitraje y Mediación}

El procedimiento en cuanto a la actuación de prueba en la LAM se encuentra reglada en tres momentos procesales:

\section{(i) Como requisito para la presentación de la demanda, contestación a la demanda, reconvención y contestación a la reconvención ${ }^{24}$;}

(ii) A ser practicadas durante el proceso arbitral ${ }^{25}$; $y$,

24. Ley de Arbitraje y Mediación, RO No. 417, 14/12/2006.

"Art. 10.- La demanda se presentará ante el director del centro de arbitraje correspondiente o ante el árbitro o árbitros independientes que se hubieren establecido en el convenio. La demanda contendrá: 1. La designación del centro o del árbitro ante quien se la propone. 2. La identificación del actor y la del demandado. 3. Los fundamentos de hecho y de derecho, expuestos con claridad y precisión. 4. La cosa, cantidad o hecho que se exige. 5. La determinación de la cuantía. 6. La designación del lugar en que debe citarse al demandado, y la del lugar donde debe notificarse al actor. 7. Los demás requisitos que la ley exija para cada caso. Se deberán, además, cumplir los requisitos señalados en el artículo 68 del Código de Procedimiento Civil. A la demanda se acompañará necesariamente el instrumento en que conste el respectivo convenio arbitral o copia auténtica de éste. Adicionalmente, se adjuntarán las pruebas y se solicitará la práctica de las diligencias probatorias que justifiquen lo aducido en la demanda".

"Art. 11.- Presentada la demanda, el director del centro de arbitraje, o si fuere el caso, el árbitro o árbitros independientes previa su posesión conforme lo establecido en el artículo 17, calificarán la demanda y mandarán a citar a la otra parte, debiendo practicarse la diligencia de citación dentro de los cinco días subsiguientes, concediéndole el término de diez días para que conteste con los mismos requisitos exigidos por el Código de Procedimiento Civil para la contestación de la demanda. Adicionalmente, se adjuntarán las pruebas y se solicitará la práctica de las diligencias probatorias, que justifiquen lo aducido en la contestación. El silencio se considerará como negativa pura y simple de los fundamentos de la demanda. Si al actor le fuere imposible determinar el domicilio del demandado, la citación se hará mediante dos publicaciones en un diario de amplia circulación en el lugar en donde se sigue el arbitraje y en el domicilio del demandado. Si el demandado no compareciere en el término de diez (10) días después de la última publicación, este hecho se tendrá como negativa pura y simple de los fundamentos de la demanda. La imposibilidad de determinación del domicilio del demandado deberá justificarse con arreglo a las normas del Código de Procedimiento Civil".

“Art. 12.- Si el demandado tuviere su domicilio fuera del lugar de arbitraje, se le concederá un término extraordinario para que conteste la demanda, el que no podrá exceder del doble del ordinario. Al contestar la demanda, el demandado podrá reconvenir exclusivamente sobre la misma materia del arbitraje siempre y cuando su pretensión pueda, conforme al convenio arbitral, someterse al arbitraje. En este caso se concederá al actor el término de diez días para que conteste la reconvención. A la reconvención y su contestación se deberá adjuntar las pruebas y solicitar las diligencias probatorias que justifiquen lo aducido en éstas".

25. Ídem.

“Art. 22.- Una vez constituido el tribunal, se fijará día y hora para la audiencia de sustanciación en la que se posesionará el secretario designado, se leerá el documento que contenga el convenio 
(iii) Como causal de nulidad si no se hubiere convocado, no se hubiere notificado la convocatoria, o si luego de convocada no se hubiere practicado las pruebas, a pesar de la existencia de hechos que deban justificarse ${ }^{26}$.

De lo anterior se desprende que la LAM nada dice sobre los requisitos para la admisibilidad de la prueba, la forma de su valoración, cuáles son las pruebas que pueden actuarse y la forma en que deberían hacerlo. Sin perjuicio de lo anterior, el artículo 38 del mismo cuerpo legal, dispone que: “[e]l arbitraje se sujetará a las normas de procedimiento señaladas en esta Ley, al procedimiento establecido en los centros de arbitraje, al determinado en el

arbitral y el tribunal resolverá sobre su propia competencia. Si el tribunal se declara competente ordenará que se practiquen en el término que el tribunal señale las diligencias probatorias solicitadas en la demanda, contestación, reconvención, modificación y contestación a ésta, siempre que fueren pertinentes, actuaciones que deberán cumplirse durante el término señalado por el tribunal arbitral. Si las partes se encontraren presentes en la audiencia podrán precisar las pretensiones y los hechos en las que ésta se fundamenta".

"Art. 23.- Si antes de la expedición del laudo, el tribunal o las partes estiman que se necesitan otras pruebas o cualquier otra diligencia para el esclarecimiento de los hechos, de oficio o a petición de parte podrá ordenar que se practiquen señalando día y hora”.

"Art. 24.- Una vez practicadas las diligencias probatorias el tribunal señalará día y hora para que las partes presenten sus alegatos en audiencia en estrados si es que lo solicitan”.

26. Ídem.

"Art. 31.- Cualquiera de las partes podrá intentar la acción de nulidad de un laudo arbitral, cuando: a) No se haya citado legalmente con la demanda y el juicio se ha seguido y terminado en rebeldía. Será preciso que la falta de citación haya impedido que el demandado deduzca sus excepciones o haga valer sus derechos y, además, que el demandado reclame por tal omisión al tiempo de intervenir en la controversia; b) No se haya notificado a una de las partes con las providencias del tribunal y este hecho impida o limite el derecho de defensa de la parte; c) Cuando no se hubiere convocado, no se hubiere notificado la convocatoria, o luego de convocada no se hubiere practicado las pruebas, a pesar de la existencia de hechos que deban justificarse; d) El laudo se refiera a cuestiones no sometidas al arbitraje o conceda más allá de lo reclamado; o, e) Cuando se hayan violado los procedimientos previstos por esta Ley o por las partes para designar árbitros o constituir el tribunal arbitral. Del laudo arbitral podrá interponerse ante el árbitro o tribunal arbitral, acción de nulidad para ante el respectivo presidente de la corte superior de justicia, en el término de diez días contado desde la fecha que éste se ejecutorió. Presentada la acción de nulidad, el árbitro o tribunal arbitral dentro del término de tres días, remitirán el proceso al presidente de la corte superior de justicia, quien resolverá la acción de nulidad dentro del término de treinta días contados desde la fecha que avocó conocimiento de la causa. La acción de nulidad presentada fuera del término señalado, se tendrá por no interpuesta y no se la aceptará a trámite. Quien interponga la acción de nulidad, podrá solicitar al árbitro o tribunal arbitral que se suspenda la ejecución del laudo, rindiendo caución suficiente sobre los perjuicios estimados que la demora en la ejecución del laudo pueda causar a la otra parte. El árbitro o tribunal arbitral, en el término de tres días, deberán fijar el monto de la caución, disponiendo la suspensión de la ejecución del laudo. La caución deberá constituirse dentro del término de tres días, contados a partir de esta notificación". 
convenio arbitral o al que las partes escojan, sin perjuicio de las normas supletorias que sean aplicables" ${ }^{27}$.

Así, es claro que la LAM, en cuanto a las reglas de procedimiento, hace, en primer lugar, una referencia a su propio contenido, que como hemos visto, regula de manera limitada la prueba; luego, al procedimiento previsto en los distintos centros de arbitraje, que será analizado más adelante; posteriormente, al acordado por las partes, y finalmente, al dispuesto en las normas supletorias que fueren aplicables, que según el artículo 37 de la LAM, son el Código Civil, Código Orgánico General de Procesos (COGEP) o Código de Comercio y otras leyes conexas, siempre que se trate de arbitraje en derecho.

\subsection{Normativa sobre procedimiento en centros de arbitraje nacionales}

A manera de ejemplo, el Reglamento de Arbitraje del Centro de Arbitraje y Conciliación de la Cámara de Comercio de Guayaquil, en sus artículo 2 y 328, dispone:

Art. 2 .- Procedimiento ante el tribunal arbitral. - El procedimiento ante el tribunal arbitral será el establecido en este reglamento, el determinado en el convenio arbitral, o el que las partes escojan directamente o por delegación al tribunal arbitral, sin perjuicio de las normas supletorias que sean aplicables. La delegación al tribunal arbitral para la determinación de las reglas del proceso, se entenderá efectuada por el solo hecho de haber sometido, las partes, el arbitraje a este Centro, dada la facultad de éstas para establecer reglas de procedimiento, conforme dispone el art. 38 de la Ley de Arbitraje y Mediación.

Art. 3.- Garantía de defensa. - Sea que el procedimiento fuere el establecido por las partes o por el tribunal, deberá garantizar los principios fundamentales del debido proceso,

27. Ídem, Artículo 38.

28. Reglamento de Arbitraje del Centro de Arbitraje y Conciliación de la Cámara de Comercio de Guayaquil, Artículo 2 y 3, 29/01/2007. 
que son inderogables, incluso para las partes. En todo caso, el tribunal arbitral deberá actuar justa e imparcialmente y asegurarse de que cada parte tenga la oportunidad suficiente para exponer su caso.

En relación concreta a la práctica de la prueba, no hay una determinación expresa en el referido reglamento salvo lo determinado en su artículo 22 sobre la práctica de las declaraciones de parte o declaraciones de testigos, en donde se establece que:

[e]n las declaraciones de partes y declaraciones de testigos, las partes no estarán obligadas a presentar pliegos de preguntas por escrito, pudiendo hacerlas en la misma audiencia, debiendo el Tribunal calificarlas en ese momento ${ }^{29}$.

El Reglamento para el funcionamiento del Centro de Arbitraje y Mediación de la Cámara de Comercio de Quito, señala:

Art. 60.- Las normas de procedimiento que rijan el arbitraje ante este Centro serán las aquí establecidas, las señaladas en la Ley de Arbitraje y Mediación y demás normas pertinentes aplicables $[\ldots]$.

Art. 61.- El proceso arbitral será oral. Las audiencias se ventilarán oralmente; al igual que las diligencias de despacho de pruebas. Todas las actuaciones se harán constar en actas a las que se adjuntaran las transcripciones mecanográficas correspondientes ${ }^{30}$.

Por su parte, el Reglamento del Centro de Arbitraje y Mediación de la Cámara de Comercio Ecuatoriana Americana, indica:

Art. 52.- Las normas de procedimiento que rijan el arbitraje ante este Centro serán las señaladas en la Ley de Arbitraje y Mediación, las establecidas en el presente reglamento y supletoriamente, en lo que no contravenga las normas y

29. Ibídem, Artículo 22.

30. Codificación del Reglamento para el funcionamiento del Centro de Arbitraje y Mediación de la Cámara de Comercio de Quito, Artículos 60 y 61, 03/07/2012. 
principios del arbitraje, las del Código de Procedimiento Civil, y en este último caso, en los procesos en Derecho.

Cuando las partes de manera expresa y de mutuo acuerdo hayan establecido las normas de procedimiento, el Director del Centro y el Tribunal Arbitral respectivamente, se reservarán el derecho de estudiar la aplicación de estas normas para proceder a su aplicación o no ${ }^{31}$.

De las normas anteriormente citadas, se desprende que estos centros de arbitraje no han desarrollado en sus reglamentos procedimientos supletorios sobre admisibilidad, tipo de pruebas o su valoración, y más bien, han dejado a las partes y a los tribunales que los determinen.

\subsection{El acuerdo de las partes como fuente del procedimiento en actuación de pruebas}

Como consecuencia de lo anterior, podemos concluir que la LAM, si bien desarrolla principios básicos para la actividad probatoria, nada dice sobre los requisitos para su admisibilidad, tipo de pruebas o valoración. Los centros de arbitraje ecuatorianos tampoco han desarrollado en sus reglamentos procedimientos supletorios sobre admisibilidad, tipo de pruebas o valoración.

Todo ello, es consecuente con la naturaleza jurídica del arbitraje, en donde prepondera la autonomía de la voluntad en cuanto al procedimiento.

No obstante, la LAM es clara al establecer que las partes pueden, en cualquier momento, ya sea a la firma del convenio o al inicio del procedimiento, pactar las normas de procedimiento que rijan los requisitos de admisibilidad, tipo de pruebas a ser presentadas, el momento procesal oportuno para su práctica

31. Reglamento para el funcionamiento del Centro de Arbitraje y Mediación (CAM) de la Cámara de Comercio Ecuatoriano Americana, Artículo 52, 26/10/2010. 
y/o los requisitos para su valoración, claro está, tomando en consideración que la frontera en la auto regulación está constituida por el aseguramiento del debido proceso y el trato equitativo de las partes.

En la práctica ecuatoriana las partes raramente realizan este tipo de acuerdo y la tendencia general ha sido que los tribunales por seguridad y en vista de la supletoriedad del COGEP asuman la aplicación de este, a pesar de que la LAM lo reserva para los casos de arbitraje en derecho.

\subsection{Normativa sobre el procedimiento de admisibilidad, tipo y valoración de la prueba en el COGEP}

Como hemos visto, entonces, en el arbitraje nacional la tendencia viene marcada por la norma supletoria para arbitrajes en derecho y en el caso de equidad ante la inercia de las partes la tendencia de los tribunales se ha encaminado a aplicar las normas del COGEP. Del referido cuerpo legal, cabe rescatar las siguientes disposiciones legales que resultan pertinentes al presente trabajo:

Sobre la actuación del tribunal arbitral, el artículo 91 del COGEP, recoge el principio iura novit curia, en virtud del cual, el tribunal está facultado para tener un rol activo respecto a las omisiones o errores de derecho que las partes incurrieren.

Art. 91.- Omisiones sobre puntos de derecho. La o el juzgador debe corregir las omisiones o errores de derecho en que hayan incurrido las personas que intervienen en el proceso. Sin embargo, no podrá otorgar o declarar mayores o diferentes derechos a los pretendidos en la demanda, ni fundar su decisión en hechos distintos a los alegados por las partes ${ }^{32}$.

32. Código Orgánico General de Procesos, Artículo 91, RO (S) No. 506, 22/05/2015. 
Asimismo, el artículo $294^{33}$ obliga al juzgador a promover la conciliación entre las partes, y también lo faculta para disponer, de oficio, o a petición de parte, que la controversia pase a un centro de mediación legalmente constituido.

Art. 294.- Desarrollo. La audiencia preliminar se desarrollará conforme con las siguientes reglas: [...]

4. La o el juzgador, de manera obligatoria, promoverá la conciliación conforme a la ley. De darse la conciliación total, será aprobada en el mismo acto, mediante sentencia que causará ejecutoria.

6. La o el juzgador, de oficio, o a petición de parte, podrá disponer que la controversia pase a un centro de mediación legalmente constituido, para que se busque un acuerdo entre las partes. En caso de que las partes suscriban un acta de mediación en la que conste un acuerdo total, la o el juzgador la incorporará al proceso para darlo por concluido.

Por su parte, el artículo 168, faculta al juez a ordenar de oficio la práctica de prueba que juzgue necesaria para el esclarecimiento de los hechos controvertidos.

Art. 168.- Prueba para mejor resolver. La o el juzgador podrá, excepcionalmente, ordenar de oficio y dejando expresa constancia de las razones de su decisión, la práctica de la prueba que juzgue necesaria para el esclarecimiento de los hechos controvertidos. Por este motivo, la audiencia se podrá suspender hasta por el término de quince días ${ }^{34}$.

El artículo 159 regula la oportunidad procesal para la práctica de la prueba, estableciendo, principalmente, que esta será de manera oral en audiencia, y además, facultando a las partes a utilizar cualquier tipo de prueba, siempre que no fuere contraria al debido proceso y la ley:

Art. 159.- Oportunidad. La prueba documental con que cuenten las partes o cuya obtención fue posible se adjuntará a la demanda, contestación a la demanda, reconvención

33. Ídem, Artículo 294.

34. Ídem, Artículo 168. 
y contestación a la reconvención, salvo disposición en contrario. La prueba a la que sea imposible tener acceso deberá ser anunciada y aquella que no se anuncie no podrá introducirse en la audiencia, con las excepciones previstas en este Código. Todo documento o información que no esté en poder de las partes y que para ser obtenida requiera del auxilio del órgano jurisdiccional, facultará para solicitar a la o al juzgador que ordene a la otra parte o a terceros que la entreguen o faciliten de acuerdo con las normas de este Código. La práctica de la prueba será de manera oral en la audiencia de juicio o en la segunda fase de la audiencia única. Para demostrar los hechos en controversia las partes podrán utilizar cualquier tipo de prueba que no violente el debido proceso ni la ley ${ }^{35}$.

Por su parte, el artículo $196^{36}$, ha diseñado el procedimiento a través del cual, en audiencia, debe producirse la prueba documental, mientras que el artículo $220^{37}$, establece la posibilidad de una de las partes de solicitar al juzgador que este último ordene a la otra, la presentación de aquellos documentos que estuvieren en su poder y fueren relevantes para la resolución del caso.

En relación con los requisitos de admisibilidad de la prueba, el artículo 160 dispone que esta deberá ser pertinente, útil, conducente y ser practicada según la ley, con lealtad y veracidad, estableciendo la facultad del juzgador de rechazar aquella prueba que, según su criterio, resulte impertinente, inútil e inconducente.

Art. 160.- Admisibilidad de la prueba. Para ser admitida, la prueba debe reunir los requisitos de pertinencia, utilidad, conducencia y se practicará según la ley, con lealtad y veracidad. La o el juzgador dirigirá el debate probatorio con imparcialidad y estará orientado a esclarecer la verdad procesal. En la audiencia preliminar o en la segunda fase de la audiencia única la o el juzgador rechazará de oficio

35. Ídem, Artículo 159.

36. Ídem, Artículo 196.

37. Ídem, Artículo 220. 
o a petición de parte la prueba impertinente, inútil e inconducente. La o el juzgador declarará la improcedencia de la prueba cuando se haya obtenido con violación de la Constitución o de la ley. Carece de eficacia probatoria la prueba obtenida por medio de simulación, dolo, fuerza física, fuerza moral o soborno. Igualmente será ineficaz la prueba actuada sin oportunidad de contradecir. La resolución por la cual la o el juzgador decida no admitir alguna prueba podrá apelarse con efecto diferido. De admitirse la apelación, la o el juzgador superior ordenará la práctica de la prueba, siempre que con ella el resultado pueda variar fundamentalmente ${ }^{38}$.

El artículo 164, dispone que para que la prueba sea valorada por el juzgador, necesariamente deberá ser solicitada, practicada e incorporada dentro de los términos señalados en el COGEP, lo que se contrapone, precisamente, con el principio de flexibilidad y autonomía de la voluntad.

Art. 164.- Valoración de la prueba. Para que las pruebas sean apreciadas por la o el juzgador deberán solicitarse, practicarse e incorporarse dentro de los términos señalados en este Código. La prueba deberá ser apreciada en conjunto, de acuerdo con las reglas de la sana crítica, dejando a salvo las solemnidades prescritas en la ley sustantiva para la existencia o validez de ciertos actos. La o el juzgador tendrá obligación de expresar en su resolución, la valoración de todas las pruebas que le hayan servido para justificar su decisión..$^{39}$

Finalmente, los artículos 165 y 169 establecen los criterios y oportunidad para la contradicción de la prueba que fuere presentada oportunamente por la otra parte. ${ }^{40}$

38. Ídem, Artículo 160.

39. Ídem, Artículo 164.

40. Ídem, Artículos 165 y 169. 


\section{Síntesis comparativa de las Reglas IBA, Praga y COGEP}

\section{Elcuadro ${ }^{41}$ que se muestra a continuación contiene un breve resumen de aquellas diferencias o características principales de las reglas de procedimiento que se han desarrollado a lo largo de este trabajo:}

\begin{tabular}{|c|c|c|}
\hline Reglas IBA & Reglas de Praga & COGEP \\
\hline & $\begin{array}{l}\text { Art. 7. Principio iura novit curia. } \\
\text { El tribunal podrá aplicar dispo- } \\
\text { siciones legales no alegadas por } \\
\text { las partes. }\end{array}$ & $\begin{array}{l}\text { Art. 91. El juez debe corregir las } \\
\text { omisiones o errores de derecho } \\
\text { en que hayan incurrido las } \\
\text { partes. }\end{array}$ \\
\hline & $\begin{array}{l}\text { Art. 9. Asistencia en la solución } \\
\text { amistosa del conflicto. }\end{array}$ & $\begin{array}{l}\text { Art. 294. En la audiencia } \\
\text { preliminar de oficio o a petición } \\
\text { de parte el juez puede disponer } \\
\text { que la controversia pase a un } \\
\text { centro de mediación. }\end{array}$ \\
\hline \multirow[t]{2}{*}{$\begin{array}{l}\text { Art. 2. El tribunal consulta } \\
\text { a las partes para normar el } \\
\text { procedimiento. }\end{array}$} & $\begin{array}{l}\text { Art. 2. Mandato expreso para } \\
\text { que el tribunal celebre una } \\
\text { conferencia para normar el } \\
\text { procedimiento. }\end{array}$ & $\begin{array}{l}\text { No hay disposición expresa en } \\
\text { la LAM, tampoco en el COGEP. }\end{array}$ \\
\hline & $\begin{array}{l}\text { Art. 3(1). Rol activo del tribunal } \\
\text { para la delimitación de los } \\
\text { hechos que estime relevantes } \\
\text { pidiendo incluso pruebas sobre } \\
\text { ellos a las partes. }\end{array}$ & \\
\hline $\begin{array}{l}\text { Art. 3(10). Pedir a cualquiera } \\
\text { de las partes que exhiba } \\
\text { documentos. } \\
\text { Art. 5.4. Ordenar que los peritos } \\
\text { se reúnan. } \\
\text { 6. Designar peritos } \\
\text { independientes. } \\
\text { Art. 7. Inspeccionar. } \\
\text { Art. 9(2). Excluir prueba. }\end{array}$ & $\begin{array}{l}\text { Art. 3(2). Solicitar prueba } \\
\text { documental o testimonios, } \\
\text { designar expertos, ordenar } \\
\text { inspecciones oculares. }\end{array}$ & $\begin{array}{l}\text { La LAM (23) y el COGEP (168) } \\
\text { posibilitan la prueba para mejor } \\
\text { resolver. }\end{array}$ \\
\hline $\begin{array}{l}\text { Art. 3(1). Dentro del plazo } \\
\text { fijado por el tribunal cada } \\
\text { parte presentará todos los } \\
\text { documentos que estén a su } \\
\text { disposición en los que basa sus } \\
\text { pretensiones. }\end{array}$ & $\begin{array}{l}\text { Art. 4(2). El tribunal debe enviar } \\
\text { la producción de pruebas en } \\
\text { forma excesiva. }\end{array}$ & $\begin{array}{l}\text { Art. 196. Producción de prueba } \\
\text { en audiencia. }\end{array}$ \\
\hline
\end{tabular}

41. Reglas de la IBA (International Bar Association) sobre Práctica de Prueba en el Arbitraje Internacional (2010); Reglas Sobre la Tramitación Eficiente de los Procedimientos en el Arbitraje Internacional (Reglas de Praga); y, Código Orgánico General de Procesos (COGEP). 


\begin{tabular}{|l|l|l|}
\hline $\begin{array}{l}\text { Art. 3(3). La solicitud de } \\
\text { producción de documentos } \\
\text { deberá contener una descripción } \\
\text { suficiente de la categoría de } \\
\text { documentos requeridos y que } \\
\text { razonablemente se creen que } \\
\text { existe. }\end{array}$ & $\begin{array}{l}\text { Art. 4(3). Una parte puede pedir } \\
\text { que la otra parte produzca } \\
\text { prueba documental. }\end{array}$ & $\begin{array}{l}\text { Art. 220. Una parte puede } \\
\text { requerir la exhibición a la otra } \\
\text { parte de un documento que } \\
\text { se encuentre en poder de esta, } \\
\text { si esta no demuestra que no } \\
\text { existe o no está en su poder, } \\
\text { se sancionará la mala fe y la } \\
\text { deslealtad procesal. }\end{array}$ \\
\hline $\begin{array}{l}\text { Art. 8(1). Dentro del plazo } \\
\text { fijado por el tribunal, cada parte } \\
\text { deberá informar acerca de los } \\
\text { testigos cuya comparecencia } \\
\text { solicita. }\end{array}$ & $\begin{array}{l}\text { Art. 5(2). El tribunal luego de } \\
\text { escuchar a las partes tomará la la } \\
\text { decisión de los testigos que exa- } \\
\text { minará en audiencia. }\end{array}$ & $\begin{array}{l}\text { Art. 159. La práctica de la } \\
\text { prueba he hará de manera oral } \\
\text { en laudiencia. }\end{array}$ \\
\hline $\begin{array}{l}\text { Art. 9. Admisibilidad y valora- } \\
\text { ción de la prueba. }\end{array}$ & $\begin{array}{l}\text { Art. 160 y 164. Admisibilidad y } \\
\text { valoración de la prueba. }\end{array}$ \\
\hline & $\begin{array}{l}\text { Art. 165 y 169. Derecho de } \\
\text { contradicción de la prueba y } \\
\text { carga de la prueba. }\end{array}$ \\
\hline
\end{tabular}

Del comparativo realizado se evidencia que tanto las Reglas IBA, las de Praga o la normativa nacional recogida en el COGEP buscan garantizar una igualdad de oportunidades para que las partes presenten y defiendan su caso.

El elemento diferenciador es el mayor o menor poder de intervención del tribunal, llegando en el caso de las Reglas de Praga a ser tan activo, que nos lleva a pensar que su aplicación tendrá como efecto migrar del sistema adversarial al sistema inquisitivo en la administración de los arbitrajes.

Asimismo, mientras las Reglas IBA se conciben como normativa referente para la práctica exclusiva de la prueba, las Reglas de Praga van más allá de ese propósito al incorporar facultades como la inclusión del principio iura novit curia o la posibilidad de que el tribunal asista para la solución amistosa del proceso.

La utilización por otro lado, de las normas del COGEP en los arbitrajes nacionales confronta a los árbitros y a las partes a decidir sobre la "seguridad" que ofrece su uso, ante una eventual ejecución por los jueces nacionales o a optar por normas que han sido diseñadas específicamente para el 
desarrollo del arbitraje, dentro de un entendimiento de lo que este es.

\section{5. ¿SE REQUIERE UNA REFORMA LEGAL PARA INCORPORAR las Reglas IBA o Praga al procedimiento arbitral NACIONAL?}

Es claro que la LAM respeta en su texto la tendencia global de que sean las partes las hacedoras de su propio procedimiento, esto, en concordancia con el principio de autonomía de la voluntad que rige el arbitraje.

No escapa a nuestro estudio el hecho de que la existencia de las Reglas de Praga se da ante una crítica al uso de las Reglas IBA, que han garantizado el protagonismo a las partes en el desarrollo del procedimiento, protagonismo que en la práctica ha llevado a que los procesos se alarguen sin que muchas veces el tribunal arbitral se atreva a entorpecer la voluntad de las partes limitando la práctica de pruebas innecesarias o asumiendo un rol mucho más preponderante en la dirección del proceso.

Este problema práctico, nos enfrenta, sin embargo, a contrariar la esencia del procedimiento arbitral al limitar a las partes la dirección del mismo, pero, debemos tener en cuenta que son las propias partes de así elegirlo quienes en ejercicio de la autonomía de la voluntad decidirán limitar esta facultad en caso de elegir las Reglas de Praga o el COGEP.

En caso de ser el tribunal arbitral quien determine la normativa aplicable, también nos encontramos ante la elección de las partes por omisión, al no ejercer su prerrogativa y dejarlo en manos de terceros.

Es evidente, entonces que, bajo la LAM vigente, son las partes las que resuelven ya sea por acción $\mathrm{u}$ omisión, si acogen una u otra norma para regir la práctica de la prueba, 
consecuentemente, la aplicación al arbitraje de las Reglas IBA o las de Praga es perfectamente factible bajo la normativa actual, y no se requiere una reforma legal para que puedan ser incorporadas a un proceso arbitral nacional si las partes así lo desean.

\section{Conclusiones}

La autonomía de la voluntad es el principio que rige el procedimiento arbitral, el aparente vacío de la ley ecuatoriana y de los reglamentos de los diferentes centros, en referencia a la prueba, confirma el respeto de estos hacia este principio rector del arbitraje.

Está en las partes decidir si usan o no las Reglas IBA o las Reglas de Praga o si se acogen a la normativa del COGEP. La utilización de las dos primeras alternativas deberá ir precedida por un proceso de divulgación de su contenido, de sus ventajas y desventajas para un procedimiento cuyo propósito es ofrecer una alternativa a las partes que asegure una justicia oportuna y eficiente; todo ello, en contraste con normas rígidas y formalistas que por esas propias características podrían estorbar la búsqueda y la obtención de decisiones justas y eficaces. 



\section{$<$ \\ caRMIGNIaNI PÉReZ}

abogados

\section{SOLUCIONES EFECTIVAS}

EN CONFLICTOS

COMPLEJOS

\section{PRÁCTICA INTERNACIONAL}

DISPUTAS EN MÚLTIPLES JURISDICCIONES BAJO DIVERSAS REGLAS ARBITRALES

\section{ESPECIALISTAS}

EN DIFERENTES TIPOS DE CONTROVERSIAS

EDUARDO CARMIGNIANI GUAYAQUIL - ECUADOR
HUGO GARCIA DIRECCIÓN

Av. NNUU y Núñez de Vela, Edif.

Metropolitan Plaza Of. 1108

QUITO-ECUADOR TELÉFONO

593-2-395-9590

EMAIL

hgarcia@caplaw.ec 
